\title{
Educação a Distância no Brasil: a expansão vertiginosa
}

\author{
Distance Education in Brazil: the vertiginous expansion \\ Educación a Distancia en Brasil: la expansión vertiginosa
}

JAIME GIOLO

Resumo: Este estudo analisa a trajetória da educação a distância no Brasil, utilizando os dados do Censo da Educação Superior do INEP. Esses dados mostram como a educação a distância expandiu-se de forma acelerada, conduzida pela iniciativa privada, que detêm, hoje, mais de $90 \%$ das matrículas. A educação a distância se destina aos segmentos populares da sociedade brasileira e, por isso, oferece cursos baratos, breves e de baixa qualidade e se concentram nas áreas de formação de professores, administração e serviço social. Nessas áreas, a educação a distância está criando sérios problemas para os cursos presenciais, podendo, mesmo inviabilizá-los ao longo dos anos. Nesse sentido, este trabalho se constitui num alerta sobre os dilemas que a educação a distância está produzindo no Brasil.

Palavras-chave: Educação a distância; Educação superior; Privatização da educação.

Abstract: This study analyzes the trajectory of distance education in Brazil, by using data from the Higher Education Census of INEP. These data show how distance education has expanded rapidly, driven by the private enterprise, which now holds more than $90 \%$ of enrollments. Distance education aims at the popular segments of Brazilian society and, therefore, offers cheap, short and low-quality courses and focuses on the areas of teacher training, administration and social service. In these areas, distance education is creating serious problems for classroom courses, and may even make them unfeasible over the years. In this sense, this work constitutes an alert about the dilemmas that distance education is producing in Brazil.

Keywords: distance education; higher education; privatization of education.

Resumen: Este estudio analiza la trayectoria de la educación a distancia en Brasil, utilizando los datos del Censo de Educación Superior del INEP. Estos datos muestran cómo la educación a distancia se ha ampliado de forma acelerada, conducida por la iniciativa privada, que actualmente posee más del $90 \%$ de las matrículas. La educación a distancia se destina a los segmentos populares de la sociedad brasileña y, por eso, ofrece cursos baratos, breves y de baja calidad y se 
concentran en las áreas de formación de profesores, administración y servicio social. En esas áreas, la educación a distancia está creando serios problemas para los cursos presenciales, pudiendo, incluso inviabilizarlos a lo largo de los años. En ese sentido, este trabajo se constituye en una alerta sobre los dilemas que la educación a distancia está produciendo en Brasil.

Palabras clave: Educación a distancia; Educación superior; Privatización de la educación.

\section{INTRODUÇÃO}

A Educação a Distância $(\mathrm{EaD})$ no Brasil é um fenômeno do século XXI. É claro que com essa afirmação deixamos de considerar certas experiências do século XX e, até, do século XIX, comumente evocadas pelos interessados em conferir a essa modalidade de ensino certo status histórico, certa legitimidade na tradição educacional brasileira. Não é o caso de ir tão longe. As experiências anteriores, além de pouco significativas no contexto da formação geral da população brasileira, foram predominantemente experimentos não formais que os distinguem completamente do que presenciamos agora, novo tempo no qual os interesses da EaD estão fundamentalmente assentados na educação formal, e, de modo especial, nos cursos superiores de graduação. Então, de imediato, delimitemos o sentido do termo "educação a distância" ao fenômeno recente e à volumosa presença da modalidade a distância na educação formal, usufruindo das mesmas prerrogativas que a modalidade presencial. Tudo o mais que acontece sob a égide da $\mathrm{EaD}$, mas que não se enquadre no terreno da educação formal, não nos interessa neste momento, não é objeto deste ensaio.

Nos relatórios estatísticos do Censo da Educação Superior do Instituto de Estudos e Pesquisas Educacionais Anísio Teixeira (INEP), os primeiros dados da educação a distância apareceram no ano 2000 e se referiam exclusivamente a instituições públicas. Os dados da iniciativa privada começaram a aparecer apenas em 2002. Isso significa que, na década de noventa do século passado, foram lançadas as bases para que esse processo adquirisse corpo material e chegasse aonde chegou. Tivemos, lá, iniciativas de várias naturezas, especialmente de ordem legal, como é o caso da Lei no 9.394/1996, LDB, do Decreto n² 2.494/1998 (este com algumas correções feitas pelo do Decreto n $\left.{ }^{\circ} 2.561 / 1998\right)$ e da Medida Provisória $\mathrm{n}^{\circ}$ 1.477-39/1997. Mas tivemos também iniciativas de ordem institucional, como foram a criação da Subsecretaria de Programas de Educação a Distância, dentro da Secretaria de Comunicação Social da Presidência da República, em 1995 (BRASIL, MP n ${ }^{\circ}$ 962/1995), e da criação da Secretaria de Educação a Distância (SEED) do Ministério da Educação, em 1996 (BASIL, Decreto nº 1.917/1996). 
Ao examinar as atribuições da Subsecretaria de Programas de Educação a Distância e, de modo especial, da Secretaria de Educação a Distância do MEC, percebe-se claramente que a compreensão à época (1995 e 1996) era de que a educação a distância e suas tecnologias deveriam consistir em programas que auxiliassem a educação brasileira (educação presencial). Não há nada, aí, que sugira a criação de uma segunda modalidade de ensino que se desenvolvesse de forma autônoma e concorrente ao ensino presencial. A dupla modalidade, com as mesmas prerrogativas, é construída, na sequência, a partir da Lei de Diretrizes e Bases da Educação Nacional (BRASIL, 1996), que veio a lume no final de 1996. $\mathrm{O}$ art. 80 da LDB determina que o poder público incentive iniciativas de educação a distância em todas as modalidades e níveis, incluindo a educação continuada, dando-lhe as prerrogativas de abertura e regimes especiais. A LDB assegura ao poder público (dos vários sistemas) as atribuições de credenciar instituições, autorizar e avaliar o desempenho dos programas e criar normas para as avaliações e o registro dos diplomas. A educação a distância recebeu, ainda, favorecimentos no que se refere a serviços de radiodifusão sonora e de sons e imagens.

O Decreto $\mathrm{n}^{\circ}$ 2.494/1998, regulamentando o art. 80 da LDB, entre questões de ordem burocrática, definiu, claramente, que a educação a distância teria regime especial, com flexibilidade de requisitos para admissão, horários e duração. Além disso, garantiu que as disciplinas cursadas numa modalidade teriam validade na outra e os certificados expedidos pelas instituições credenciadas para a oferta de educação a distância portariam validade nacional. Com essas garantias, a instituições de educação superior tinham tudo do que precisavam para promover uma enorme demanda por credenciamentos e autorizações, muito embora mantivessem sempre viva uma resistência (ou ao menos uma queixa) contra os processos burocráticos de controle feitos pelo poder público.

Precisamos dizer duas palavras também sobre a Medida Provisória $\mathrm{n}^{\circ}$ 1.477-39, de 8 de agosto de 1997, que, após sucessivas reedições mensais, foi convertida na Lei $\mathrm{n}^{\circ}$ 9.879/1999. Essa medida provisória vinha sendo editada desde, pelo menos, julho de 1996 (BRASIL, MP no 1.477-25), tratando sempre das mensalidades escolares. Na edição n 39 , em agosto de 1997, a Medida Provisória introduziu algo novo:

Art. 10. A Lei $\mathrm{n}^{\circ}$ 9.131, de 24 de novembro de 1995, passa a vigorar acrescida dos seguintes arts. $8^{\circ}[\ldots]$ : Art. $8^{\circ}$ As pessoas jurídicas de direito privado, mantenedoras de instituições de ensino superior, previstas no inciso II do art. 19 da Lei no 9.394, de 20 de dezembro de 1996, poderão assumir qualquer das formas admitidas em direito, de natureza civil ou comercial e, quando constituídas como fundações, serão regidas pelo disposto no art. 24 do Código Civil Brasileiro. 
Até esse momento, somente poderiam ocupar-se da educação as pessoas jurídicas com fins ideais, ou seja, sem fins lucrativos. Com o dispositivo da Medida Provisória transcrito acima, as entidades com fins lucrativos também puderam atuar na Educação Superior. Isso explica, em parte, por que a iniciativa privada fez do ensino superior de graduação o terreno fundamental de seus investimentos, deixando em banho morno o Ensino Fundamental e o Ensino Médio. Isso explica também o fato de chegarmos a 2015 com as matrículas de educação a distância controladas pela iniciativa privada à razão de $90 \%$.

Em 2002, o diagnóstico produzido pela Comissão Assessora criada por meio da Portaria n ${ }^{\circ} 335$, de 6 de fevereiro de 2002, do Ministro da Educação Paulo Renato de Souza, para elaborar proposta de alteração da regulamentação da educação a distância no nível superior e dos procedimentos de supervisão e avaliação do Ensino Superior a distância, considerava ainda inexpressiva a oferta da educação a distância no Brasil. Até aquele momento a modalidade a distância era usada, principalmente, pelas instituições públicas que, em parceria com Estados e Municípios, cuidavam de dar formação superior aos milhares de professores que não tinham graduação e, segundo a LDB, deveriam obtê-la até 2006 (BRASIL, Lei n 9 9.394/1996, art. 87, \ 4º). Isso era, sem dúvida verdade, mas, de forma alguma, o processo estava travado. A Comissão não prestou a devida atenção aos movimentos que a iniciativa privada fazia no sentido de lançar altos voos na oferta da EaD. Havia, em 2002, milhares de pedidos de credenciamento de instituições e de autorização de cursos no âmbito do MEC. À medida que foram sendo liberados, houve uma desenfreada corrida às minas de ouro recémdescobertas. É o que se verá nos tópicos seguintes.

\section{O QUE DIZEM OS NÚMEROS?}

\section{Bloco 1: 2000-2002}

De acordo com o Censo da Educação Superior do Inep/MEC, em 2000, havia, no Brasil, sete instituições credenciadas para a oferta de cursos a distância, todas públicas (Universidade Federal de Ouro Preto, Universidade Estadual do Ceará, Fundação Universidade do Estado de Santa Catarina, Universidade Federal do Paraná, Universidade Federal de Alagoas, Universidade do Estado de Mato Grosso, Universidade Estadual de Ponta Grossa). Essas sete instituições tinham dez cursos autorizados (mas nem todos com matrículas realizadas) e matricularam 1.682 alunos. Os cursos ofertados e com matrículas ativas eram: Pedagogia, com 1.383 alunos, e Programa especial de formação pedagógica, com 299 alunos. 
No ano seguinte, eram dez instituições credenciadas, todas públicas (somaram-se às anteriormente citadas, a Universidade Estadual do Maranhão, a Universidade Federal Fluminense e a Universidade Federal do Espírito Santo), com 16 cursos autorizados (mas nem todos com matrículas realizadas) e 5.359 alunos matriculados. Os cursos com matrículas ativas eram: Curso Normal Superior, com 1.793 alunos; Educação Básica, com 1.011 alunos; Pedagogia, com 2.396 alunos; e Programa especial de formação pedagógica, com 159 alunos.

Em 2002, as instituições somavam 25; dessas, 16 eram instituições públicas (sete estaduais e nove federais) e nove privadas. Juntas, ofertaram 46 cursos de graduação e matricularam 40.714 alunos. Dessas matrículas, as instituições públicas tinham $84,30 \%$ (54,91\%, as estaduais; e 29,39\%, as federais) e as privadas tinham 15,70\%. Quanto aos cursos, é importante notar que, por iniciativa da Faculdade de Administração de Brasília, um bacharelado (Administração, com 385 matrículas) foi introduzido num cenário, até então voltado integralmente para a formação de professores. Os cursos de 2002, com as respectivas matrículas, estão arrolados na tabela a seguir:

\section{Tabela 1: Distribuição dos Cursos de EaD com as respectivas matrículas e percentuais sobre o total - Brasil, 2002}

\begin{tabular}{|l|l|l|l|l|l|}
\hline CURSOS & MATR. & \%/TOTAL & CURSOS & MATR. & \%/TOTAL \\
\hline Pedagogia & 21.872 & 53,7 & Administração & 385 & 0,9 \\
\hline Curso Normal Superior & 13.168 & 32,3 & Matemática & 160 & 0,4 \\
\hline Educação Básica - Anos Iniciais & 2.770 & 6,8 & $\begin{array}{l}\text { Licenciatura em } \\
\text { Biologia }\end{array}$ & 150 & 0,4 \\
\hline $\begin{array}{l}\text { Magistério das séries iniciais do } \\
\text { Ensino Fundamental }\end{array}$ & 1.295 & 3,2 & $\begin{array}{l}\text { Ciências } \\
\text { (Magister) }\end{array}$ & 116 & 0,3 \\
\hline Programa Especial de Form. Pedag. & 798 & 2,0 & Total & $\mathbf{4 0 . 7 1 4}$ & $\mathbf{1 0 0 , 0}$ \\
\hline
\end{tabular}

Fonte: Inep/MEC. Censo da Educação Superior, 2002

Compulsando as informações do Censo da Educação Superior, pode-se observar que, em 2000, para as 6.430 vagas oferecidas, as Instituições de Educação Superior (IES) obtiveram 8.002 candidatos inscritos, mas ingressaram apenas 5.287 alunos. Isso dá uma média de 1,24 candidatos por vaga e um percentual de 17,78 de vagas não preenchidas. Em 2001, o resultado foi melhor: foram oferecidas 6.856 vagas, inscreveram-se 13.967 candidatos e se matricularam 6.618 alunos. Isso dá uma média de 2,04 candidatos por vaga, e um percentual de 3,47 de vagas não preenchidas. Em 2002, os números voltaram ao patamar de 2000 e indicam uma tendência que, dali para diante, só tenderá a se fortalecer: uma oferta enorme para uma demanda moderada. As IES, em 2002, ofereceram 24.389 
vagas, obtiveram 29.702 inscrições, mas matricularam apenas 20.685 alunos. Isso dá uma média de 1,22 candidatos por vaga e percentual de 15,19 de vagas não preenchidas.

Do que foi dito até aqui, três tendências se insinuaram no horizonte da educação brasileira a partir da entrada em cena da educação a distância. A primeira tendência é a de que ela, a educação a distância, apesar de ser concebida, a partir da LDB, para ocupar-se de todos os níveis da escolarização, estruturou-se para constituir um grande mercado educacional na Educação Superior e, nesse terreno, atuar com prioridade absoluta nos cursos de graduação. A segunda tendência é a de que a iniciativa privada promoverá uma oferta extraordinária de vagas e atrairá para si o grande continente da demanda, de forma ainda mais expressiva do que já fez com a educação presencial. A terceira tendência é a de que a educação a distância, sob o patrocínio privado, concentra-se-á nos cursos de fácil oferta (de poucos investimentos em laboratórios e materiais pedagógicos - cursos de cartilhas) e voltados para segmentos populares da sociedade.

Analisaremos, agora, os dados de três anos específicos, 2005, 2010 e 2015, para observar como essas tendências estão materializando-se e qual o grau já alcançado.

\section{Bloco 2: 2005}

Em 2005, a par do expressivo crescimento da educação a distância em relação a 2002, à razão de $144,0 \%$ para IES credenciadas, 310,9\% para cursos ofertados, e 181,6\% para alunos matriculados, houve uma inversão saliente quanto à participação da iniciativa privada frente à oferta pública. Se não, vejamos a tabela seguinte:

\section{Tabela 2: Distribuição das IES, Cursos e Matrículas (EaD) por categoria administrativa, com percentuais de participação em relação ao total - Brasil, 2005}

\begin{tabular}{|c|c|c|c|c|c|c|}
\hline CAT. ADM. & IES & \%/TOTAL & CURSOS & \%/TOTAL & MATR. & \%/TOTAL \\
\hline Estaduais & 9 & 14,8 & 41 & 21,7 & 37.377 & 32,6 \\
\hline Federais & 14 & 23,0 & 25 & 13,2 & 15.740 & 13,7 \\
\hline Municipais & 1 & 1,6 & 7 & 3,7 & 1.398 & 1,2 \\
\hline Privadas & 37 & 60,7 & 116 & 61,4 & 60.127 & 52,4 \\
\hline Total & 61 & 100,0 & 189 & 100,0 & 114.642 & 100,0 \\
\hline
\end{tabular}

Fonte: Inep/MEC. Censo da Educação Superior, 2005 
A próxima tabela apresenta a distribuição das matrículas da educação a distância, em 2005, por área do conhecimento específica, segundo a classificação do INEP. Nesse ano, a formação de professores, embora mantivesse o maior percentual das matrículas (68,39), já apareceu cedendo espaço a outra área com vocação para ocupar enorme fatia do mercado educacional: Comércio e Administração (30,33\% das matrículas). Lembre-se de que, em 2002, o curso de Administração tinha apenas, $0,9 \%$ das matrículas.

\section{Tabela 3: Distribuição das matrículas (EaD), por área específica (classificação do INEP), e percentuais sobre o total- Brasil, 2005}

\begin{tabular}{|c|c|c|c|c|c|}
\hline $\begin{array}{c}\text { ÁREA ESPECÍFICA } \\
\text { (CLASSIFICAÇÃO INEP) }\end{array}$ & MATR. & \%/TOTAL & $\begin{array}{c}\text { ÁREA ESPECÍFICA } \\
\text { (Classificação } \\
\text { Inep) }\end{array}$ & MATR. & \%/TOTAL \\
\hline $\begin{array}{c}\text { Formação de prof. e } \\
\text { ciências da educação }\end{array}$ & 78.402 & 68,39 & $\begin{array}{c}\text { Ciências sociais e } \\
\text { comportamentais }\end{array}$ & 130 & 0,11 \\
\hline Comércio e administração & 34.772 & 30,33 & $\begin{array}{c}\text { Agric., flor. e } \\
\text { recursos pesqueiros }\end{array}$ & 44 & 0,04 \\
\hline Serviços pessoais & 1.017 & 0,89 & $\begin{array}{c}\text { Engenharia } \\
\text { e profissões } \\
\text { correlatas }\end{array}$ & 5 & - \\
\hline Computação & 272 & 0,24 & Total & 114.642 & 100.00 \\
\hline
\end{tabular}

Fonte: Inep/MEC. Censo da Educação Superior, 2005

No que concerne à oferta e à procura, houve, em 2005, um descolamento descomunal entre os dois fatores. Para um total de 423.411 vagas oferecidas, as IES conseguiram inscrever nos processos seletivos apenas 233.626 candidatos $(0,6$ candidato por vaga) e matricular tão somente 127.014 alunos ( 0,3 matrícula por vaga oferecida). O melhor desempenho ficou com as IES federais que ofertaram 4.646 vagas, obtiveram 18.323 inscrições (3,9 candidatos por vaga) e matricularam 4.475 alunos (0,96 matrícula por vaga). Em seguida, vêm as IES estaduais com oferta de 28.270 vagas, obtendo 32.637 inscrições (1,2 candidatos por vaga) e matriculando 25.133 alunos (0,89 matrícula por vaga). O grande descompasso manifestou-se na IES municipal e nas IES privadas. A municipal (Universidade do Sul de Santa Catarina) ofertou 4.700 vagas, obteve 2.074 inscrições $(0,4$ candidato por vaga) e matriculou 1.244 alunos (0,26 matrícula por vaga). As IES privadas ofertaram 385.795 vagas, obtiveram 180.592 inscrições ( 0,5 candidato por vaga) e matricularam 96.162 alunos (0,25 matrícula por vaga). No geral, em 2005, 70,0\% das vagas oferecidas pela educação a distância no país não foram preenchidas. Nas IES estaduais, $11,1 \%$ das vagas ficaram sem preenchimento; nas IES federais, 3,7\%; na IES municipal, 73,5\%; e, nas IES privadas, 75,1\%. 
Em 2005, das 114.642 matrículas em EaD, 101.327 (88,4\%) estavam em cursos de licenciatura e $13.315(11,6 \%)$ em cursos de bacharelado. Os cursos superiores de tecnologia ainda não apareciam nesse cenário.

Comparando a educação superior presencial e a educação superior a distância, em 2005, temos o seguinte quadro:

Tabela 4: Distribuição das matrículas presenciais em EaD, por rede e grau acadêmico, com respectivos percentuais - Brasil, 2005

\begin{tabular}{|c|c|c|c|c|}
\hline $\begin{array}{c}\text { REDEIGRAU } \\
\text { ACADÊMICO }\end{array}$ & PRESENCIAL & EAD & $\%$ PRES. & $\%$ EAD \\
\hline Privada & 3.260 .967 & $\mathbf{6 0 . 1 2 7}$ & 98,2 & $\mathbf{1 , 8}$ \\
\hline Bacharelado & 2.386 .659 & 3.628 & 99,8 & 0,2 \\
\hline $\begin{array}{c}\text { Bacharelado e } \\
\text { Licenciatura }\end{array}$ & 196.563 & 130 & 99,9 & 0,1 \\
\hline Licenciatura & 518.184 & 56.369 & 90,2 & 9,8 \\
\hline Tecnólogo & 159.561 & - & 100,0 & - \\
\hline Pública & 1.192 .189 & $\mathbf{5 . 4 5 1 5}$ & 95,6 & $\mathbf{4 , 4}$ \\
\hline Bacharelado & 603.822 & 9.687 & 98,4 & 1,6 \\
\hline $\begin{array}{c}\text { Bacharelado e } \\
\text { Licenciatura }\end{array}$ & 159.912 & - & 100,0 & - \\
\hline Licenciatura & 373.745 & 44.828 & 89,3 & 10,7 \\
\hline Tecnólogo & 54.710 & - & 100,0 & - \\
\hline TOTAL & 4.453 .156 & 114.642 & 97,5 & $\mathbf{2 , 5}$ \\
\hline
\end{tabular}

Fonte: Inep/MEC. Censo da Educação Superior, 2005

\section{Bloco 3: 2010}

Cinco anos depois, em 2010, as instituições credenciadas para a oferta da educação a distância, em relação a 2005, haviam-se ampliado em 121,3\%, os cursos haviam crescido $392,1 \%$ e as matrículas $711,4 \%$. A próxima tabela mostra os dados principais de 2010, merecendo destaque o número absoluto das matrículas que chegaram às portas de um milhão (930.179) e o percentual dessas matrículas abocanhado pela iniciativa privada $(80,5)$. 
Tabela 5: Distribuição das IES, Cursos e Matrículas (EAD) por categoria administrativa, com percentuais de participação em relação ao total Brasil, 2010

\begin{tabular}{|c|c|c|c|c|c|c|}
\hline CAT. ADM. & IES & \%/TOTAL & CURSOS & \%/TOTAL & MATR. & \%/TOTAL \\
\hline Estaduais & 18 & 13,3 & 106 & 11,4 & 76.414 & 8,2 \\
\hline Federais & 48 & 35,6 & 302 & 32,5 & 104.722 & 11,3 \\
\hline Municipais & 1 & 0,7 & 17 & 1,8 & 466 & 0,1 \\
\hline Privadas & 68 & 50,4 & 506 & 54,4 & 748.577 & 80,5 \\
\hline Total & 135 & 100,0 & 930 & 100,0 & 930.179 & 100,0 \\
\hline
\end{tabular}

Fonte: Inep/MEC. Censo da Educação Superior, 2010

A próxima tabela apresenta a distribuição das matrículas da educação a distância, em 2010, por área do conhecimento específica, segundo a classificação do INEP. Nesse ano, a formação de professores, embora mantivesse o maior percentual das matrículas $(45,73)$, já não demonstrava ter a maioria absoluta da preferência; a área de Comércio e Administração, com 37,58\% das matrículas, já lhe toca os calcanhares. Outra área que entrou como um vendaval na educação a distância foi a de Serviço Social. Matrículas no curso de Serviço Social a distância apareceram, pela primeira vez no Censo da Educação Superior, em 2007 e já, em 2010, ocuparam o terceiro lugar na preferência nacional, com 74.474 matrículas (8.01\% do total).

Tabela 6: Distribuição das matrículas (EaD), por área específica (classificação do INEP) e percentuais sobre o total - Brasil, 2010

\begin{tabular}{|c|c|c|c|c|c|}
\hline $\begin{array}{c}\text { ÁREA } \\
\text { ESPECÍFICA } \\
\text { (INEP) }\end{array}$ & MATR. & \%/TOTAL & $\begin{array}{c}\text { ÁREA } \\
\text { ESPECÍFICA } \\
\text { (INEP) }\end{array}$ & MATR. & \%/TOTAL \\
\hline $\begin{array}{c}\text { Formação de } \\
\text { professores } \\
\text { e ciências da } \\
\text { educação }\end{array}$ & 425.355 & 45,73 & $\begin{array}{c}\text { Ciências sociais e } \\
\text { comportamentais }\end{array}$ & 1.741 & 0,19 \\
\hline $\begin{array}{c}\text { Comércio e } \\
\text { administração }\end{array}$ & 349.543 & 37,58 & Artes & 1.566 & 0,17 \\
\hline Serviço social & 74.474 & 8,01 & $\begin{array}{c}\text { Produção e } \\
\text { processamento }\end{array}$ & 838 & 0,09 \\
\hline Computação & 28.039 & 3,01 & Saúde & 667 & 0,07 \\
\hline $\begin{array}{c}\text { Proteção } \\
\text { ambiental }\end{array}$ & 18.721 & 2,01 & $\begin{array}{c}\text { Arquitetura e } \\
\text { construção }\end{array}$ & 453 & 0,05 \\
\hline $\begin{array}{c}\text { Serviços de } \\
\text { segurança }\end{array}$ & 10.964 & 1,18 & Direito & 98 & 0,01 \\
\hline
\end{tabular}


Tabela 6: Distribuição das matrículas (EaD), por área específica (classificação do INEP) e percentuais sobre o total - Brasil, 2010

\begin{tabular}{|c|c|c|c|c|c|}
\hline $\begin{array}{c}\text { ÁREA } \\
\text { ESPECÍFICA } \\
\text { (INEP) }\end{array}$ & MATR. & \%/TOTAL & $\begin{array}{c}\text { ÁREA } \\
\text { ESPECÍFICA } \\
\text { (INEP) }\end{array}$ & MATR. & \%/TOTAL \\
\hline $\begin{array}{c}\text { Engenharia } \\
\text { e profissões } \\
\text { correlatas }\end{array}$ & 10.810 & 1,16 & Ciências físicas & 72 & 0,01 \\
\hline $\begin{array}{c}\text { Humanidades e } \\
\text { letras }\end{array}$ & 2.962 & 0,32 & $\begin{array}{c}\text { Serviços de } \\
\text { transportes }\end{array}$ & 30 & - \\
\hline $\begin{array}{c}\text { Serviços } \\
\text { pessoais }\end{array}$ & 1.995 & 0,21 & $\begin{array}{c}\text { Jornalismo e } \\
\text { informação }\end{array}$ & 21 & - \\
\hline $\begin{array}{c}\text { Agric., flor. } \\
\text { e recursos } \\
\text { pesqueiros }\end{array}$ & 1.830 & 0,20 & Total & 930.179 & 100.00 \\
\hline
\end{tabular}

Fonte: Inep/MEC. Censo da Educação Superior, 2010

A respeito da oferta e da procura, o descolamento descomunal entre os dois fatores, verificado em 2005, manteve-se, em 2010, ligeiramente acrescido. Para um total de 1.634.118 vagas oferecidas, as IES conseguiram inscrever nos processos seletivos apenas 690.921 candidatos (0,4 candidato por vaga) e matricular tão somente 380.328 alunos (0,2 matrícula por vaga oferecida). O melhor desempenho ficou com as IES federais que ofertaram 34.127 vagas, obtiveram 92.350 inscrições (2,71 candidatos por vaga) e matricularam 33.143 alunos ( 0,97 matrícula por vaga). Em seguida, vêm as IES estaduais com oferta de 12.303 vagas, obtendo 30.538 inscrições (2,48 candidatos por vaga) e matriculando 6.481 alunos (0,53 matrícula por vaga). O maior descompasso manifestou-se na IES municipal e nas IES privadas. A municipal (Universidade de Taubaté) ofertou 5.760 vagas, obteve 1.204 inscrições ( 0,2 candidato por vaga) e matriculou 550 alunos ( 0,1 matrícula por vaga). As IES privadas ofertaram 1.581 .928 vagas, obtiveram 566.829 inscrições ( 0,36 candidato por vaga) e matricularam 340.154 alunos (0,22 matrícula por vaga). No geral, em 2010, 76,7\% das vagas oferecidas pela educação a distância no país não foram preenchidas. Nas IES estaduais, $47,3 \%$ das vagas ficaram sem preenchimento; nas IES federais, $2,9 \%$; na IES municipal, 90,5\% e nas IES privadas, 78,5\%.

Em 2010, do total de 930.179 matrículas em EaD, 426,241 (45,7\%) estavam em cursos de licenciatura, $268.173(28,8 \%)$ em cursos de bacharelado e $235.765(25,35 \%)$ em cursos superiores de tecnologia.

Comparando-se a Educação Superior presencial e a Educação Superior a distância, em 2010, temos a tabela 7, merecendo destaque o índice de matrículas alcançado pela $\mathrm{EaD}: 14,6 \%$ do total, contra 2,5\% em 2005. As licenciaturas, na 
rede privada, que, em 2005, tinham nos cursos a distância 9,8\% das matrículas, passam a ter, em 2010, 40,8, seguida pelos cursos superiores de tecnologia que alcançaram $32,0 \%$ das matrículas na oferta a distância.

\section{Tabela 7: Distribuição das matrículas presenciais em EaD, por rede e grau acadêmico, com respectivos percentuais - Brasil, 2010}

\begin{tabular}{|c|c|c|c|c|}
\hline $\begin{array}{c}\text { REDEIGRAU } \\
\text { ACADÉMICO }\end{array}$ & PRESENCIAL & EAD & \% PRES. & $\%$ EAD \\
\hline Privada & 3.987 .424 & 748.577 & 84,2 & 15,8 \\
\hline Bacharelado & 3.064 .659 & 212.133 & 93,5 & 6,5 \\
\hline Licenciatura & 470.011 & 323.257 & 59,2 & 40,8 \\
\hline Tecnólogo & 452.699 & 213.187 & 68,0 & 32,0 \\
\hline Publica & 1.461 .696 & 181.602 & 88,9 & 11,1 \\
\hline Bacharelado & 893.885 & 56.040 & 94,1 & 5,9 \\
\hline Licenciatura & 458.737 & 102.984 & 81,7 & 18,3 \\
\hline Áreas básicas & 15.929 & - & 100,0 & - \\
\hline Tecnólogo & 93.145 & 22.578 & 80,5 & 19,5 \\
\hline TOTAL & $\mathbf{5 . 4 4 9 . 1 2 0}$ & 930.179 & 85,4 & 14,6 \\
\hline
\end{tabular}

Fonte: Inep/MEC. Censo da Educação Superior, 2010

\section{Bloco 4: 2015}

Passados mais cinco anos, em 2015, as instituições credenciadas para a oferta da educação a distância, em relação a 2010, haviam-se ampliado em índices bem mais modestos do que no período anterior: $43,0 \%$ de crescimento para o conjunto das instituições, $16,7 \%$ para as IES estaduais, $27,1 \%$ pra as IES federais, $58,8 \%$ para as IES privadas e 200,0\% para as IES municipais. Este último índice destoou dos demais, em função de ter havido, no período anterior, apenas uma instituição municipal ofertando educação a distância, número ampliado para três no segmento temporal em análise. Em relação ao número de cursos e matrículas, verificaram-se índices negativos nas IES estaduais e federais, embora os índices gerais tenham sido positivos: $58,39 \%$ de crescimento para cursos e $49,84 \%$ para as matrículas. No período, o índice da evolução dos cursos nas IES estaduais foi de $-8,49 \%$ e, nas federais, de $-2,32 \%$. Por seu turno, nas IES municipais o crescimento dos cursos foi de 76,47\% e, nas privadas, de $107,71 \%$. Quanto às matrículas, o índice das IES estaduais foi de $-42,43 \%$ e, das federais, $-22,21 \%$. Houve crescimento expressivo nas municipais $(531,33 \%)$ e, mais modesto, nas privadas $(69,04 \%)$. 
A próxima tabela mostra os dados principais de 2015, merecendo destaque a privatização crescente e avassaladora da educação a distância, com as IES privadas dominando $90,8 \%$ das matrículas.

Tabela 8: Distribuição das IES, Cursos e Matrículas (EaD) por categoria administrativa, com percentuais de participação em relação ao total Brasil, 2015

\begin{tabular}{|c|c|c|c|c|c|c|}
\hline CAT. ADM. & IES & \%/TOTAL & CURSOS & \%/TOTAL & MATR. & $\% /$ TOTAL \\
\hline Estaduais & 21 & 10,9 & 97 & 6,6 & 43.988 & 3,2 \\
\hline Federais & 61 & 31,6 & 295 & 20,0 & 81.463 & 5,8 \\
\hline Municipais & 3 & 1,6 & 30 & 2,0 & 2.942 & 0,2 \\
\hline Privadas & 108 & 56,0 & 1051 & 71,4 & 1.265 .359 & 90,8 \\
\hline Total & 193 & 100,0 & 1473 & 100,0 & 1.393 .752 & 100,0 \\
\hline
\end{tabular}

Fonte: Inep/MEC. Censo da Educação Superior, 2010

A próxima tabela apresenta a distribuição das matrículas da educação a distância, em 2015, por área do conhecimento específica, segundo a classificação do INEP. No último período, a área de formação de professores (40,43\% das matrículas) foi ultrapassada pela área de Comércio e Administração (41,56\%). Serviço Social se manteve na terceira posição com 6,93\% das matrículas (quase cem mil alunos). Vale a pena prestar atenção também para as áreas da Computação, Proteção Ambiental e Engenharia que, oferecendo bacharelados e cursos superiores de tecnologia, poderão ganhar muita força num futuro próximo.

Tabela 9: Distribuição das matrículas (EaD), por área específica (classificação do INEP), e seus respectivos percentuais em relação ao total - Brasil, 2015

\begin{tabular}{|c|c|c|c|c|c|}
\hline $\begin{array}{c}\text { ÁREA ESPECÍFICA } \\
\text { (INEP) }\end{array}$ & MATR. & $\% / T O T A L$ & $\begin{array}{c}\text { ÁREA ESPECÍFICA } \\
\text { (INEP) }\end{array}$ & MATR. & $\%$ /TOTAL \\
\hline $\begin{array}{c}\text { Comércio e } \\
\text { administração }\end{array}$ & 579.274 & 41,56 & $\begin{array}{c}\text { Arquitetura e } \\
\text { construção }\end{array}$ & 6.659 & 0,48 \\
\hline $\begin{array}{c}\text { Formação de } \\
\text { professores e ciências } \\
\text { da educação }\end{array}$ & 563.551 & 40,43 & $\begin{array}{c}\text { Ciências sociais e } \\
\text { comportamentais }\end{array}$ & 3446 & 0,25 \\
\hline Serviço social & 96.638 & 6,93 & $\begin{array}{c}\text { Agric., flor. e rec. } \\
\text { pesqueiros }\end{array}$ & 2419 & 0,17 \\
\hline Computação & 35.334 & 2,54 & $\begin{array}{c}\text { Matemática e } \\
\text { estatística }\end{array}$ & 1032 & 0,07 \\
\hline Proteção ambiental & 27.671 & 1,99 & $\begin{array}{c}\text { Serviços de } \\
\text { transportes }\end{array}$ & 753 & 0,05 \\
\hline
\end{tabular}


Tabela 9: Distribuição das matrículas (EaD), por área específica (classificação do INEP), e seus respectivos percentuais em relação ao total - Brasil, 2015

\begin{tabular}{|c|c|c|c|c|c|}
\hline $\begin{array}{l}\text { ÁREA ESPECÍFICA } \\
\text { (INEP) }\end{array}$ & MATR. & \%/TOTAL & $\begin{array}{l}\text { ÁREA ESPECÍFICA } \\
\text { (INEP) }\end{array}$ & MATR. & \%/TOTAL \\
\hline $\begin{array}{c}\text { Engenharia e } \\
\text { profissões correlatas }\end{array}$ & 27.126 & 1,95 & Direito & 508 & 0,04 \\
\hline Serviços de segurança & 18.945 & 1,36 & $\begin{array}{l}\text { Jornalismo e } \\
\text { informação }\end{array}$ & 353 & 0,03 \\
\hline Serviços pessoais & 15.526 & 1,11 & Artes & 243 & 0,02 \\
\hline Humanidades e letras & 7.237 & 0,52 & $\begin{array}{l}\text { Produção e } \\
\text { processamento }\end{array}$ & 137 & 0,01 \\
\hline Saúde & 6.833 & 0,49 & Ciências físicas & 67 & - \\
\hline & & & Total & 1.393 .752 & 100,00 \\
\hline
\end{tabular}

Fonte: Inep/MEC. Censo da Educação Superior, 2015

Tomando, pela última vez, a relação entre oferta e procura, mantevese, em 2015, o descolamento descomunal verificado nos anos anteriores. Em 2015, para um total de 2.782.480 vagas oferecidas, as IES conseguiram inscrever nos processos seletivos apenas 1.656 .470 candidatos (0,6 candidato por vaga) e matricular tão somente 694.559 alunos ( 0,2 matrícula por vaga oferecida). O melhor desempenho ficou, desta vez, com as IES estaduais com oferta de 20.369 vagas, obtendo 42.809 inscrições (2,10 candidatos por vaga) e matriculando 15.434 alunos (0,76 matrícula por vaga). Em seguida, vêm as IES federais, que ofertaram 23.297 vagas, obtiveram 50.702 inscrições (2,18 candidatos por vaga) e matricularam 14.010 (0,60 matrícula por vaga). O maior descompasso manifestouse nas IES municipais e nas IES privadas. O pior desempenho ficou com as IES municipais (Universidade de Taubaté, Universidade do Contestado e Universidade Municipal de São Caetano do Sul), que ofertaram 7.258 vagas, obtiveram 1.968 inscrições $(0,27$ candidato por vaga) e matricularam 879 alunos $(0,12$ matrícula por vaga). Em seguida, num patamar ligeiramente acima, as IES privadas ofertaram 2.731.556 vagas, obtiveram 1.560.991 inscrições (0,57 candidato por vaga) e matricularam 664.236 alunos (0,24 matrícula por vaga). No geral, em 2010, 75,0\% das vagas oferecidas pela educação a distância no país não foram preenchidas. Nas IES estaduais, $24,2 \%$ das vagas ficaram sem preenchimento; nas IES federais, $39,9 \%$; nas IES municipais, $87,9 \%$ e nas IES privadas, $75,7 \%$.

Em 2015, do total de 1.393 .752 matrículas em EaD, 565.000 (40,5\%) estavam em cursos de licenciatura, $436.078(31,3 \%)$ em cursos de bacharelado e $392.674(28,2)$ em cursos superiores de tecnologia. 
Das 114 denominações de cursos (segundo classificação da OCDE), envolvendo Bacharelados, Licenciaturas e Tecnlológicos, com matrículas ativas em EaD, 30 desses cursos, juntos, alcançaram 1.299.563 matrículas, ou seja, 93,3\% do total de matrículas de EaD. A relação desses cursos, por modalidade, com suas respectivas matrículas está na próxima tabela.

\section{Tabela 10: Relação dos 10 cursos de Bacharelado, Licenciatura e Tecnólogo com maior numero de matrículas - Brasil, 2015}

\begin{tabular}{|c|c|c|c|c|c|}
\hline BACHARELADOS & MATR. & LICENCIATURAS & MATR. & TECNÓLOGOS & MATR. \\
\hline Administração & 181.250 & Pedagogia & 341.887 & $\begin{array}{c}\text { Gestão de pessoal } \\
\text { (RH) }\end{array}$ & 87.062 \\
\hline Serviço social & 96.638 & $\begin{array}{l}\text { For. prof. de língua/ } \\
\text { literatura }\end{array}$ & 48.377 & Empreendedorismo & 62.026 \\
\hline Ciências contábeis & 92.357 & $\begin{array}{l}\text { For. prof. educação } \\
\text { física }\end{array}$ & 41.416 & Gestão logística & 35.834 \\
\hline $\begin{array}{l}\text { Administração } \\
\text { pública }\end{array}$ & 15.406 & For. prof. de história & 31.547 & $\begin{array}{l}\text { Administração } \\
\text { pública }\end{array}$ & 33.644 \\
\hline $\begin{array}{l}\text { Engenharia de } \\
\text { produção }\end{array}$ & 12.014 & $\begin{array}{l}\text { For. prof. de } \\
\text { matemática }\end{array}$ & 28.567 & Gestão ambiental & 27.671 \\
\hline Engenharia civil & 6.651 & For. prof. de biologia & 16.185 & $\begin{array}{l}\text { Anál. e Desen. de } \\
\text { Sistemas }\end{array}$ & 25.574 \\
\hline Teologia & 6.202 & $\begin{array}{l}\text { For. prof. de } \\
\text { geografia }\end{array}$ & 16.103 & $\begin{array}{l}\text { Marketing e } \\
\text { propaganda }\end{array}$ & 19.640 \\
\hline $\begin{array}{l}\text { Sistemas de } \\
\text { informação }\end{array}$ & 5.044 & $\begin{array}{l}\text { For. prof. de artes } \\
\text { visuais }\end{array}$ & 7.692 & Gestão financeira & 17.710 \\
\hline Educação física & 4.869 & For. prof. de filosofia & 7.383 & $\begin{array}{l}\text { Gestão da } \\
\text { informação }\end{array}$ & 14.794 \\
\hline Engenharia elétrica & 2.742 & $\begin{array}{l}\text { For. prof. de } \\
\text { computação }\end{array}$ & 2.242 & $\begin{array}{l}\text { Saúde e seg. no } \\
\text { trabalho }\end{array}$ & 11.036 \\
\hline TOTAL & 423.173 & TOTAL & 541399 & TOTAL & 334.991 \\
\hline
\end{tabular}

Fonte: Inep/MEC. Censo da Educação Superior, 20015

Comparando-se a Educação Superior presencial e a Educação Superior a distância, em 2015, temos o quadro seguinte, onde se pode ver o encorpamento da $\mathrm{EaD}$ no contexto da graduação brasileira, com $17,4 \%$ do total das matrículas, cabendo destaque à área das licenciaturas com 38,4\% das matrículas (na iniciativa privada, $53,4 \%$ e aos cursos superiores de tecnologia com $38,9 \%$ das matrículas (na iniciativa privada, $44,4 \%$ ): 
Tabela 11: Distribuição das matrículas presenciais e EaD, por rede e grau acadêmico, com respectivos percentuais - Brasil, 2015

\begin{tabular}{|c|c|c|c|c|}
\hline $\begin{array}{c}\text { REDEIGRAU } \\
\text { ACADÉMICO }\end{array}$ & PRESENCIAL & EAD & $\%$ PRES. & $\%$ EAD \\
\hline Privada & 4.809 .793 & 1.265 .359 & 79,2 & 20,8 \\
\hline Bacharelado & 3.913 .832 & 407.299 & 90,6 & 9,4 \\
\hline Áreas básicas & 155 & - & 100,0 & - \\
\hline Licenciatura & 415.895 & 477.038 & 46,6 & 53,4 \\
\hline Tecnológico & 479.911 & 381.022 & 55,7 & 44,3 \\
\hline Publica & 1.823 .752 & 128.393 & 93,4 & 6,6 \\
\hline Bacharelado & 1.166 .241 & 28.779 & 97,6 & 2,4 \\
\hline Áreas básicas & 28.919 & - & 100,0 & - \\
\hline Licenciatura & 491.035 & 87.962 & 84,8 & 15,2 \\
\hline Tecnológico & 137.557 & 11.652 & 92,2 & 7,8 \\
\hline TOTAL & 6.633 .545 & 1.393 .752 & 82,6 & 17,4 \\
\hline
\end{tabular}

Fonte: Inep/MEC. Censo da Educação Superior, 20015

\section{O QUE SE PODE DIZER A PARTIR DOS NÚMEROS?}

A partir do mapa traçado acima, agregando-se outros dados e informações, pode-se chegar às seguintes constatações:

\section{PRIMEIRA CONSTATAÇÃO}

O mercado educacional criado, em poucos anos, pela EaD no Brasil é gigantesco, apesar de a oferta não ter qualquer correspondência efetiva com a demanda. De qualquer forma, quase um milhão e meio de matrículas (dados de 2015) é um quantitativo nada desprezível. A concentração das matrículas nos cursos de licenciatura, tecnológicos, administração e serviço social mostram a intenção que sempre regeu a expansão da EaD: atingir as classes populares. A propaganda e as promoções que as instituições fazem nos seus sites não deixam dúvidas. A título de exemplo, a Unopar anuncia o processo seletivo para 2018 acompanhado da informação de que a primeira mensalidade será a partir de R \$ 59,00 (https:// vestibular. unoparead.com.br/); a Unip a distância promete mensalidades a partir de $\mathrm{R} \$ 149,00$, sendo que a primeira será de, apenas, R \$ 60,00 (https://www.unip. br/ead). A Rede Laureate no Brasil divulga mensalidades a partir de R\$159,00 (https://www.eadlaureate. com.br). Além dos valores reduzidos, as instituições acenam com sistemas próprios de bolsas, créditos educativos e financiamentos de diferentes modalidades. Diante disso, é impossível não deduzir que a Educação 
a Distância está produzindo uma partição no sistema educacional brasileiro para além da partição tradicional e mais radical do que esta, que sempre destinou uma educação de boa qualidade para ricos e uma educação aligeirada e fraca para pobres. A educação a distância carrega ainda mais nessas tintas.

Mais grave, entretanto, é o fato de haver uma expropriação de recursos dos segmentos populares, sem que nada lhes seja entregue, nem diploma nem formação. É o que aconteceu, por exemplo, com os 260.091 alunos que, em 2015 apareceram no Censo da Educação Superior do Inep com matrícula trancada e os 448.622 alunos com matrícula desvinculada, ou seja: aqueles, em vias de desligamento definitivo do curso; estes, tendo-o já abandonado. Outra forma de observar esse fenômeno é pelo exame da dinâmica dos ingressos e das conclusões de curso na educação a distância. Os cursos superiores na modalidade a distância têm duração que varia de dois a quatro anos. Muitas instituições anunciam cursos de tecnólogo com duração de dois anos, a maioria dos bacharelados com duração de três anos e alguns bacharelados com duração de quatro anos. Tomando-se como média a duração de três anos, não estaremos, de forma alguma, sendo injustos com a EaD. Partindo dessa média de três anos de duração, poderemos observar que, em 2010, ingressaram 380.385 alunos, mas, em 2012, concluíram o curso 174.334 estudantes, ou seja, 54,2\% não aparecem como concluintes. Em 2011, ingressaram 431.631 alunos, mas, em 2013, concluíram 161.098 estudantes, ou seja, 62,7\% não aparecem como concluintes. Em 2012, ingressaram 542.696 alunos, mas, em 2014, concluíram o curso 189.792 estudantes, ou seja, 65,0\% não aparecem como concluintes. Finalmente, em 2013, ingressaram 515.410 alunos, mas, em 2015, concluíram o curso 233.723 estudantes, ou seja, 54,7\% não aparecem como concluintes. Note-se que o padrão se repete com ligeiras variações, o que leva a que se admita que, sistematicamente, mais da metade dos alunos não chegam a obter o respectivo diploma.

Considerando essa dinâmica que leva a índices tão baixos (menos de $50 \%$ ) de conclusão dos cursos em EaD e considerados os registros do Censo da Educação Superior, mostrando que, em 2015, 708.713 alunos estavam desvinculados ou com matrícula trancada, é forçoso admitir que esse quantitativo de alunos pagou, no mínimo, a matrícula, mas muitos, por certo, pagaram outras parcelas antes de desistirem. E o que receberam em troca? Praticamente, nada. Trata-se de uma transferência de recursos, sem contraprestação, dos pobres em benefício de entidade e corporações que, em poucos anos, acumularam cifras monetárias astronômicas. Não pode a EaD argumentar, a seu favor, que seu aluno participa de um ambiente formativo estruturado de forma a permitir-lhe acúmulos progressivos de formação e que, portanto, o aluno que evade leva consigo um patrimônio formativo equivalente ao tempo que esteve formalmente vinculado 
ao curso. O método da EaD está assentado no isolamento do aluno e em sua autonomia, em seu autodidatismo. O aluno que não consegue operar com esse diapasão é o que evade e, portanto, não constitui patrimônio formativo algum durante o tempo em que mantém vínculos formais com o curso. O dramático de tudo isso é de ordem estrutural e, por ora, só o podemos enunciar por meio dos seguintes questionamentos: 'Estaríamos constituindo, no Brasil, uma engrenagem na qual o aluno desistente é peça funcional no esquema que financia a EaD? Será esse aluno tão (ou mais) interessante, em termos financeiros, do que o aluno perseverante?' Um estudo mais alentado de economia da educação poderia revelar, de forma adequada, essa engrenagem, ao tempo em que nos levaria, quiçá, a responder estas outras perguntas: 'por que um sistema (estamos nos referindo à EaD privada) opera, se mantém e progride preenchendo, a cada processo seletivo, apenas, aproximadamente, $25 \%$ das vagas que oferece e, depois, suporta uma evasão que ultrapassa a cifra de 50\%? Qual é a relação das vagas ofertadas com a planilha de custos das instituições ofertantes? Qual é a relação entre os ingressos, a planilha de custos e a margem de lucro? Qual é a relação entre a evasão, a planilha de custos e margem de lucro?

\section{SEGUNDA CONSTATAÇÃO}

Há motivos para se afirmar que, no terreno ao qual ela tem sucesso, a EaD, no Brasil, não é complementar à educação presencial, mas concorrente dela. A maior parte dos polos de EaD não está situada em lugares onde inexistem instituições com oferta presencial. Ao contrário, os polos estão muito próximos das salas de aula presenciais. As próprias instituições que tradicionalmente ofertam cursos presenciais estão, progressivamente, fazendo ofertas a distância e fechando, ou mantendo perspectiva de fechar, as ofertas presenciais. Se tomarmos os cinco cursos mais representativos na EaD, responsáveis, em 2015, por 697.843 matrículas $(50,1 \%$ do total), e os compararmos com sua oferta na modalidade presencial, poderemos perceber como o crescimento das matrículas em EaD corresponde a um decréscimo proporcional nas matrículas dos cursos presenciais. Esse fenômeno é muito preocupante, porque poderá representar um risco de desmonte não apenas desses cursos presenciais, mas das próprias instituições nos casos em que haja dependência financeira expressiva desses e de outros cursos que sofrem a concorrência da oferta a distância. Se, de alguma forma, esses riscos forem afastados, não se afastarão facilmente os prejuízos que o Brasil terá ao incorporar na educação básica um corpo docente formado, prioritariamente, nos 
cursos a distância ou de ter os profissionais da assistência social, em sua maioria, formados nessa modalidade. Com o curso de Administração poderá acontecer a mesma coisa, no médio prazo.

Os gráficos a seguir apresentam a evolução dos cursos de Pedagogia, Administração, Serviço Social, Letras e Matemática, de 2010 a 2015, tanto na modalidade a distância quanto na modalidade presencial (dados do Censo da Educação Superior do Inep). Note-se que, no curso de Serviço Social, a modalidade a distância tem maior número de matrículas do que a modalidade presencial, durante todo o período, com tendência a um distanciamento progressivo. O curso de Pedagogia, por sua vez, passa a apresentar o mesmo perfil desde 2014, quando a quantidade de matrículas na modalidade a distância ultrapassou a quantidade de matrículas na modalidade presencial, também com tendência a um afastamento progressivo. Nos demais cursos, a quantidade de matrículas na modalidade presencial é, ainda, bem maior do que a quantidade de matrículas em EaD, mas a tendência de aproximação é visível, seja pela queda constante das matrículas presenciais, seja pela relativa ascensão das matrículas a distância.

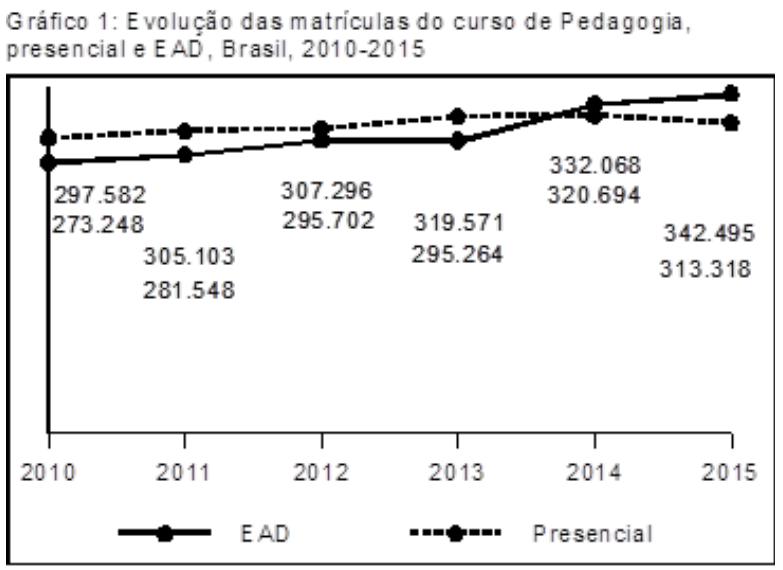

Fante: MECInep. Censa da Educaçãa Superiar, $2010-2015$ 
Gráfico 2: E volução das m atrículas do curso de $\mathrm{Adm}$ in istração, presen cial e EAD, Brasil, 2010-2015

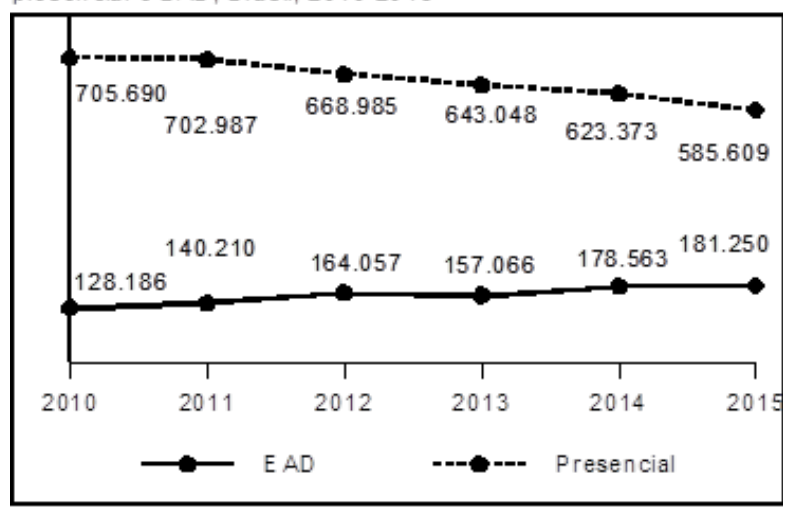

Fante: MEC/lnep. Censa da Educação Superiar, 2010-2015

Gráfico 3: E volução das m atrículas do curso de Serviço Social, presencial e EAD, Brasil, 2010-2015

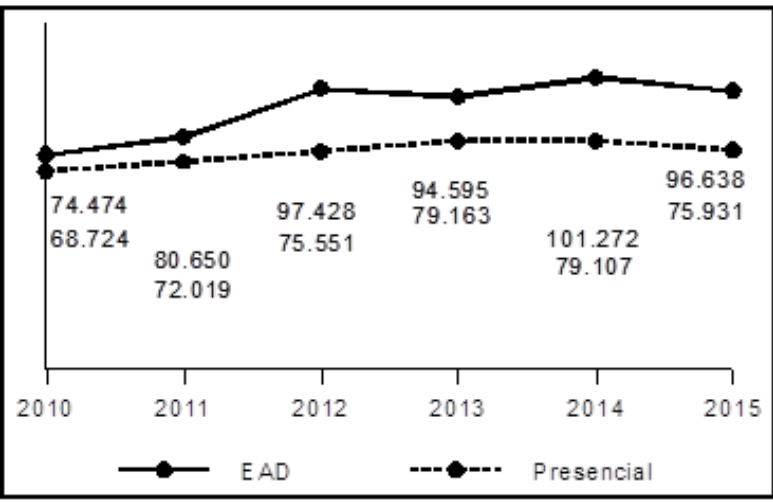

Fante: MEC/lnep. Censa da Educaçãa Superiar, 2010-2015

Gráfico 4: E volução das m atrículas do curso de Letras presencial e EAD, Brasil, 2010-2015

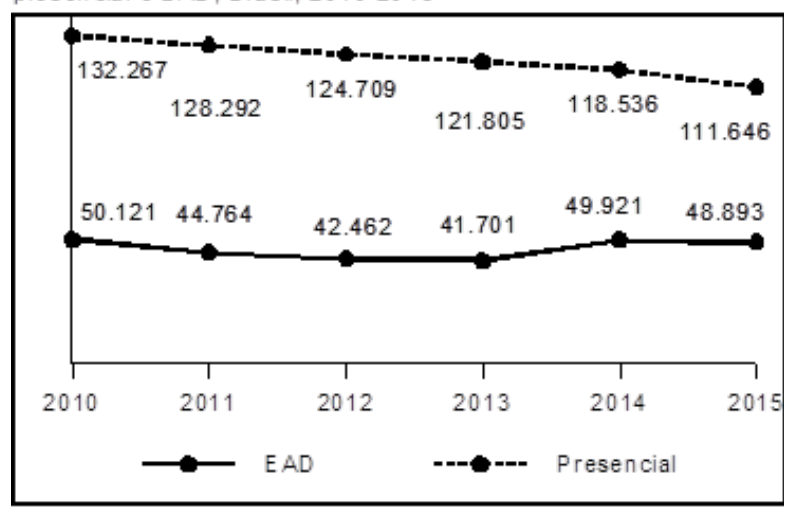

F ante: MEC/lnep. Censa da Edu caçãa Superiar, $2010-2015$ 


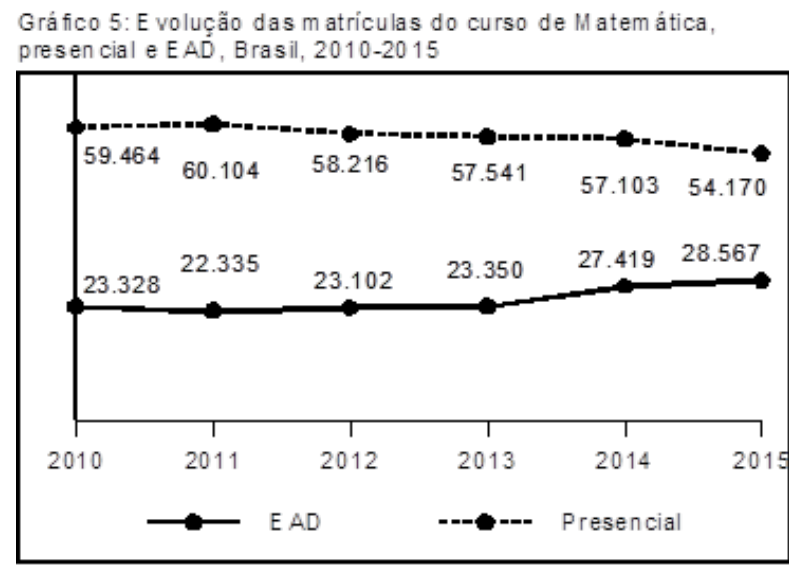

Fante: MEC/lnep. Censo da Educação Superiar, 2010-2015

Mas não é em todos os cursos que a educação a distância se coloca como concorrente da educação presencial. Embora a tentativa seja ampla, as possibilidades são limitadas. Dos 114 diferentes cursos, ativos em 2015, apenas 21 tiveram oferta de vagas acima de 50 mil (todos na área de formação de professores, administração/gestão e serviço social). Outros 14 tiveram oferta de vagas que variaram de 10 mil a 50 mil. Apenas 13 cursos ofereceram entre 5 mil e dez mil vagas. Abaixo disso, 24 cursos ofereceram entre mil e 5 mil vagas e, finalmente, 42 cursos ofertaram menos de mil vagas cada um. Interessante é observar que em alguns cursos, embora houvesse a tentativa de oferta ampla, a procura foi tão inexpressiva que, possivelmente, sejam deixados de lado num futuro próximo; por exemplo: Economia ofertou 50.429 vagas, mas matriculou 1.573 alunos; Licenciatura em Sociologia ofertou 47.731 vagas, mas matriculou 2.614 alunos; Tecnologia em Agronegócio ofertou 41.779 vagas, mas matriculou 1.423 alunos; Enfermagem ofertou 17.522 vagas, mas matriculou 676 alunos; Engenharia da Computação ofertou 13.645 vagas, mas matriculou 1.332 alunos; Turismo ofertou 4.520 vagas, mas matriculou 159 alunos; Engenharia Mecânica ofertou 3.494 vagas, mas matriculou 232 alunos; e Engenharia de Controle e Automação ofertou 2.000 vagas, mas matriculou apenas quatro alunos.

Há, inclusive, um conjunto de cursos para os quais as IES não abriram qualquer vaga, levando a crer que estão em extinção. São eles: Geografia (da Natureza), Gestão de empresas, Gestão de supermercados, Tecnologia da informação, Mercadologia e Tecnologia de alimentos.

Sofrível é também o desempenho de vários cursos de formação de professores, como Filosofia, Sociologia (já citada acima), Música, Educação artística, Química, Física, Informática, Ciências, Educação especial e Artes cênicas, com ingressos que vão, pela ordem, de 3.175 a zero. 
Com bom potencial de expansão estão os cursos: Empreendedorismo, Gestão logística, Administração pública, Análise e desenvolvimento de sistemas, Gestão ambiental, Gestão financeira, Marketing e propaganda, Gestão da informação, Engenharia de produção, Saúde e segurança no trabalho, Segurança pública, Teologia e Engenharia civil, a maioria tecnológicos, com ingressos, em 2015, que vão, pela ordem, de 37.846 a 4.716.

O curso de Direito, que, na modalidade presencial, foi um dos motores da expansão da educação superior privada, ao lado do curso de Administração e do curso de Pedagogia, parece não dar sinais evidentes de que decolará na EaD. Isso, provavelmente, deva-se ao fato de que a autorização dos cursos de Direito requer o parecer favorável da OAB (Ordem dos Advogados do Brasil) e, ali, poderá estar a muralha de seu represamento.

\section{TERCEIRA CONSTATAÇÃO}

Se dependesse dos índices de evolução dos cursos mostrados nos gráficos acima, poder-se-ia prever um colapso nos próximos anos, pois a modalidade presencial mostra tendência de queda geral e mesmo a modalidade a distância sinaliza tendências de estagnação. Considerando-se, entretanto, o conjunto da Educação Superior, os índices de crescimento são ainda expressivos, embora não se igualem aos períodos recentes de maior expansão. De 2010 a 2015, as matrículas dos cursos superiores de graduação cresceram 25,3\%, no geral; as matrículas presenciais cresceram $21,1 \%$ e as de $\mathrm{EaD}$ cresceram 49,7\%. Os impactos da crise econômica e política, bem como os impactos da nova orientação administrativa do Brasil, claramente elitista, poderão agregar mais força à tendência de queda dos índices de expansão da Educação Superior. Os indicadores de crescimento das matrículas de 2014 para 2015 já revelam sinais nessa direção. Com efeito, diferentemente dos anos anteriores, cujos percentuais foram bem maiores, de 2014 para 2015, o crescimento das matrículas na graduação foi de, apenas, 2,5\% (2,3\%, na modalidade presencial, e 3,9\% na modalidade a distância).

No que tange à educação a distância, a crise econômica e, principalmente, as medidas tomadas no âmbito do Golpe Parlamentar, como a Emenda Constitucional $n^{\circ} 95$, de 15 de dezembro de 2016, vão reduzir drasticamente as possibilidades da EaD pública. A educação a distância inverterá completamente a perspectiva inicial, quando toda a oferta era pública: passará a ser quase que exclusivamente privada. Ocorre que a educação a distância pública necessita de aportes específicos para operar, aportes sem os quais não há que se esperar 
a continuidade da experiência. Os números do último período (2010-2015) já mostram uma queda acentuada nos anos finais do segmento, como pode ser observado na tabela a seguir.

\section{Tabela 12: Distribuição das matrículas EaD, por categoria administrativa, com percentuais de evolução anuais- Brasil, 2010-2015}

\begin{tabular}{|c|c|c|c|c|c|c|}
\hline CAT. ADM & $\mathbf{2 0 1 0}$ & $\mathbf{2 0 1 1}$ & $\mathbf{2 0 1 2}$ & $\mathbf{2 0 1 3}$ & $\mathbf{2 0 1 4}$ & $\mathbf{2 0 1 5}$ \\
\hline Estadual & 76.414 & 71.152 & 64.778 & 46.929 & 39.181 & 43.988 \\
\hline Federal & 104.722 & 105.850 & 102.211 & 92.344 & 96.482 & 81.463 \\
\hline \% de evolução - Estadual & $-6,9$ & $-9,0$ & $-27,6$ & $-16,5$ & 12,3 \\
\hline \multicolumn{2}{|r|}{$\%$ de evolução - Federal } & 1,1 & $-3,4$ & $-9,7$ & 4,5 & $-15,6$ \\
\hline
\end{tabular}

Fonte: Inep/MEC. Censo da Educação Superior, 2015

A privatização total da educação a distância é, portanto, uma perspectiva real e, considerando-se o ambiente de crise atual, impondo a redução de curtos de toda ordem, há que se esperar uma migração ainda maior (onde for possível, bem entendido, como se mostrou acima) da oferta presencial para a oferta a distância.

\section{CONCLUSÃO}

Em estudos publicados anteriormente, tematizamos a 'Educação a distância e a formação de professores' e, também, a 'Educação a Distância: tensões entre o público e o privado’ (as referências completas dessas publicações estão ao final deste artigo). Muitos dos argumentos e reflexões postos nesses textos são ainda válidos, mas como eles estão disponíveis, inclusive eletronicamente, ficamos escusados de retomá-los aqui. Basta-nos, por ora, assinalar que o Estado brasileiro foi incapaz de conduzir o processo de expansão da educação a distância com o mínimo de controle e direcionamento, deixando que se construísse, por obra de iniciativas particulares, um "Titanic" que, agora, está desgovernado e ingovernável. Experimentamos, inclusive, certo bloqueio mental que nos impede de propor qualquer coisa, pois, ao que tudo indica, a embarcação alcançou um ponto da rota do qual já não parece razoável tentar retroagir, nem estacionar nem desviar o curso para um lado ou para outro. Cabe-nos, pelo menos, a prerrogativa de estudar e entender esse processo que veio sendo conduzido ao abrigo de névoas espessas, mas que devagar vão se dissipando. Foi essa mirada interpretativa que tentamos fazer neste estudo. É preciso mais, entretanto. São necessárias muitas luzes para enxergar longe e profundo. Fica o desafio. 


\section{REFERÊNCIAS}

BRASIL. Decreto $n^{\circ} 7.480$, de 16 de maio de 2011. Aprova a Estrutura do Ministério da Educação. Brasília, DF, mai 2011.

BRASIL. Decreto $n^{\circ}$ 5.622, de 19 de dezembro de 2005. Regulamenta o art. 80 da Lei no 9.394, de 20 de dezembro de 1996, que estabelece as diretrizes e bases da educação nacional. Brasília, DF, dez 2005.

BRASIL, MEC/SESU. Relatório da Comissão Assessora para Educação Superior a Distância, agosto de 2002. Disponível em: http://portal.mec.gov.br/sesu/ arquivos/ pdf/EAD.pdf

BRASIL, MEC. Portaria $n^{\circ}$ 335, de 6 de fevereiro de 2002. Cria a Comissão Assessora com a finalidade de apoiar a Secretaria de Educação Superior na elaboração de proposta de alteração das normas que regulamentam a oferta de educação a distância no nível superior. Brasília, DF, fev 2002.

BRASIL. Decreto n 2.561, de 27 de abril de 1998. Altera a redação dos arts. 11 e 12 do Decreto n. ${ }^{\circ}$ 2.494, de 10 de fevereiro de 1998, que regulamenta o disposto no art. 80 da Lei n. ${ }^{\circ}$ 9.394, de 20 de dezembro de 1996. Brasília, DF, abr 1998.

BRASIL. Decreto $n^{\circ} 2.494$, de 10 de fevereiro de 1998. Regulamenta o art. 80 da Lei $\mathrm{n}^{\circ}$ 9.394, de 20 de dezembro de 1996, e dá outras providências. Brasília, DF, dez 1998.

BRASIL. Medida Provisória nº 1.477-39, de 8 de agosto de 1997. Dispõe sobre o valor total anual das mensalidades escolares e dá outras providências. Brasília, DF, ago 1997.

BRASIL. Lei ño.394, de 20 de dezembro de 1996. Estabelece as diretrizes e bases da educação nacional. Brasília, DF, dez 1996.

BRASIL. Medida Provisória ñ 962, de 30 de março de 1995. Dispõe sobre a organização da Presidência da, no uso República e dos Ministérios, e dá outras providências. Brasília, DF, mar 1995.

BRASIL, MEC/INEP. Censo da Educação Superior, 2000. Em: http://portal.inep. gov.br/web/guest/microdados. 
BRASIL, MEC/INEP. Censo da Educação Superior, 2001. Em: http://portal.inep. gov.br/web/guest/microdados.

BRASIL, MEC/INEP. Censo da Educação Superior, 2002. Em: http://portal.inep. gov.br/web/guest/microdados.

BRASIL, MEC/INEP. Censo da Educação Superior, 2003. Em: http://portal.inep. gov.br/web/guest/microdados.

BRASIL, MEC/INEP. Censo da Educação Superior, 2005. Em: http://portal.inep. gov.br/web/guest/microdados.

BRASIL, MEC/INEP. Censo da Educação Superior, 2010. Em: http://portal.inep. gov.br/web/guest/microdados.

BRASIL, MEC/INEP. Censo da Educação Superior, 2011. Em: http://portal.inep. gov.br/web/guest/microdados.

BRASIL, MEC/INEP. Censo da Educação Superior, 2012. Em: http://portal.inep. gov.br/web/guest/microdados.

BRASIL, MEC/INEP. Censo da Educação Superior, 2013. Em: http://portal.inep. gov.br/web/guest/microdados.

BRASIL, MEC/INEP. Censo da Educação Superior, 2014. Em: http://portal.inep. gov.br/web/guest/microdados.

BRASIL, MEC/INEP. Censo da Educação Superior, 2015. Em: http://portal.inep. gov.br/web/guest/microdados.

GIOLO. Jaime. A educação a distância e a formação de professores. Educação $\ll$ Sociedade. Campinas, vol. 29 no 105 Campinas Set./Dez. p. 1211-1234. 2008. Também disponível em: http://www.scielo.br/scielo.php?script= sci_arttext\&pi $\mathrm{d}=$ S0101-73302008000400013

GIOLO. Jaime. Educação a distância: tensões entre o público e o privado. Educação \& Sociedade. Campinas, vol. 31 nº 113 Out./Dez. p. 1271-1298. 2010. Também disponível em: http://www.scielo.br/scielo.php?script= sci_arttext\&pi $\mathrm{d}=$ S0101-73302010000400012 
JAIME GIOLO é Professor da Universidade Federal da Fronteira Sul (UFFS), doutor em História e Filosofia da Educação pela Universidade de São Paulo, Pós Doutor em Educação Superior Brasileira pela Unicamp, atualmente no cargo de Reitor da UFFS. E-mail: giolo@uffs.edu.br

Recebido em fevereiro de 2018 Aprovado em abril de 2018 